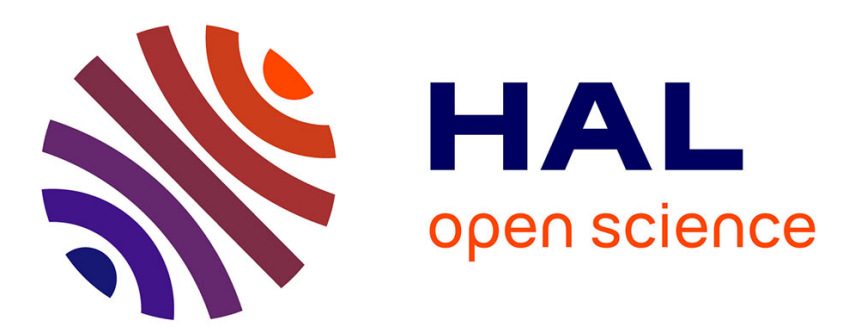

\title{
Clustering and the spatial distribution of contact spots at a real un-dismantled electrical contact interface
}

\author{
J Swingler
}

\section{To cite this version:}

J Swingler. Clustering and the spatial distribution of contact spots at a real un-dismantled electrical contact interface. Journal of Physics D: Applied Physics, 2010, 43 (14), pp.145302. 10.1088/0022$3727 / 43 / 14 / 145302$. hal-00569572

\section{HAL Id: hal-00569572 \\ https://hal.science/hal-00569572}

Submitted on 25 Feb 2011

HAL is a multi-disciplinary open access archive for the deposit and dissemination of scientific research documents, whether they are published or not. The documents may come from teaching and research institutions in France or abroad, or from public or private research centers.
L'archive ouverte pluridisciplinaire $\mathbf{H A L}$, est destinée au dépôt et à la diffusion de documents scientifiques de niveau recherche, publiés ou non, émanant des établissements d'enseignement et de recherche français ou étrangers, des laboratoires publics ou privés. 


\title{
Clustering and the spatial distribution of contact spots at a real un-dismantled electrical contact interface
}

\author{
J. Swingler \\ School of Engineering Sciences, University of Southampton, Southampton, SO17 1BJ, \\ United Kingdom. \\ Email: swingler@soton.ac.uk
}

\begin{abstract}
Contact maps of an electrical interface are acquired using an X-Ray Computer Tomography (CT) technique without the need for dismantling the specimens. These maps consist of approximately $1500 \times 1500$ pixels with each pixel relating to an $8.0 \mu \mathrm{m}$ by $8.0 \mu \mathrm{m}$ by $8.0 \mu \mathrm{m}$ volume at the interface. The specimens consist of bolting a cable lug to a printed circuit board at various contact normal forces of between $0.8-3.2 \mathrm{kN}$. The contact maps reveal a complex network of contacting "islands" with meandering perimeters consisting of contacting "peninsulas" and non-contacting "fjords". The fractal characteristics of the spot spatial distribution show similar behaviour to the fractal characteristics of the spot size distribution.
\end{abstract}

Keywords. Contact, contact maps, clustering, X-ray tomography.

\section{Introduction}

Real surfaces have a roughness on many scales. This is particular important on the microscopic scale which influences mechanical contact when two surfaces are brought together. This mechanical contact only occurs in a specific number of areas on the apparent area of contact as visualized by Thomas and Probert. Indentations indicating contact are observed but the contacting system had to be dismantled for analysis (micrographs reproduced in [1]). Swingler and Lalechos [2] have visualized the area of contact with contact maps taken by using an X-Ray Computer Tomography (CT) technique without dismantling the specimens. The mechanical area of contact is determined which is in close agreement with a plastic deformation model of contact surface. In addition, the spot size distribution shows a Korcak empirical number-area behaviour, analogues to the size distribution of islands on Earth [3], from which fractal characteristics can be obtained. Equation 1 shows this relationship as the spot size cumulative distribution function for the number of spots of a particular size $A_{i}$ which are equal or larger than a reference size $[2,4]$. The fractal dimension is given by $\mathrm{D}$ and $\mathrm{A}_{\mathrm{L}}$ is the largest spot size on the specimen. 


$$
N\left(A_{i} \geq A_{r e f}\right)=\left(\frac{A_{L}}{A_{r e f}}\right)^{D / 2}
$$

Majumdar and Bhushan [5] highlight the importance of the size and spatial distributions of contact spots in developing theories in tribology and contact physics. The spot spatial distribution is important in studying the stress and dynamic interactions between contacting spots. In an electrical contact, spot spatial distribution is also important for determining the contact resistance. Greenwood developed an expression for contact resistance by approximating the electrical potential field due to a current flow through the cluster of spots [6]. Others have developed this further to model the contact resistance from spot distributions [7-10].

This paper takes further the work already presented on the visualization and size distribution of contact spots at a real un-dismantled bolted electrical interface [2] and focuses on clustering and the spatial distribution of these contact spots. The interface is mapped using an X-ray CT technique leaving it undisturbed in order to give a realistic representation of the area of contact under the mechanically loaded conditions. An initial investigation into the effect of clustering using the mapped data on contact resistance is presented.

\section{Experimental Arrangement and Methodology}

A bolted connector arrangement used to join a cable lug to a printed circuit board (PCB) is investigated. Aluminium nuts and bolts are used due to their low density compared to copper making it easier for the X-ray CT technique to acquire images [11]. The bolt has a screw diameter of $6 \mathrm{~mm}$, length of $100 \mathrm{~mm}$ and is tightened to between $1 \pm 0.05$ to $4 \pm 0.05 \mathrm{Nm}(0.8-3.2 \mathrm{kN})$. Torque values are converted to contact normal force values using an appropriation equation with the "nut factor" of $0.21 \pm 0.01$ [12]. Figure 1 illustrates the arrangement of fixing the cable lug to the PCB with the bolt, nut and two types of washers [13]. A tripedal wavy washer makes contact with the cable lug forming the interface under investigation.

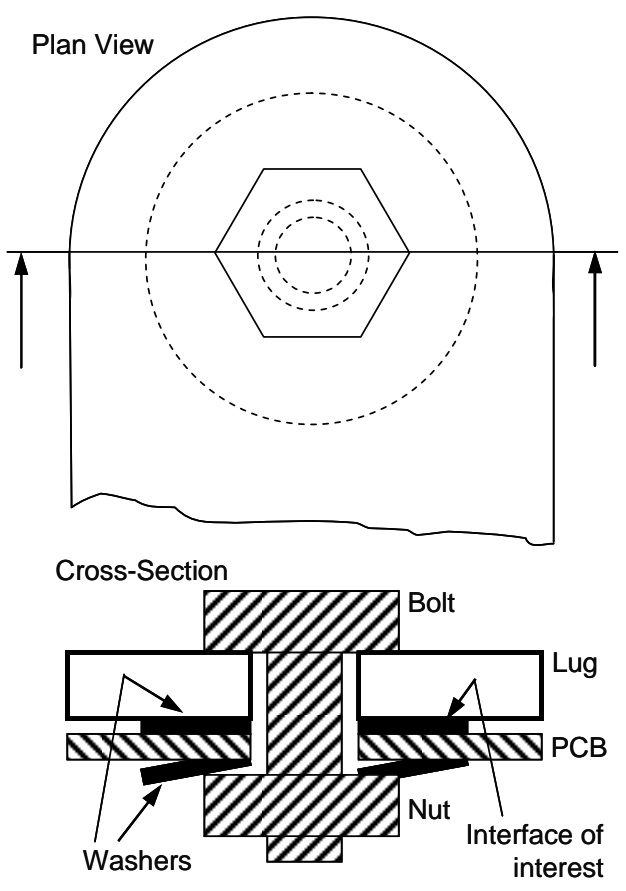

Figure 1 Bolted Connector Arrangement 


\subsection{Visualization technique}

The visualization technique consists of several stages starting with acquiring X-Ray images of the specimen using a CT scanner. The CT scanner is an X-Tek CT 160Xi $\mu$ CT fitted with a tungsten $\mathrm{X}$-ray target. The X-ray source is set to $160 \mathrm{kV}$, which can give a $5 \mu \mathrm{m}$ focus capability and feature recognition down to $1 \mu \mathrm{m}$. The CT scanner acquires between 3,000 and 3,500 axial 2D X-ray images by rotating the specimen through $360^{\circ}$.

The axial 2D X-ray images are then reconstructed as a 3D model of the bolted arrangement using the "CTPro" software. "3D Studio Max" software is then used to generate 2D slice images from the $3 \mathrm{D}$ reconstruction model which gives multiple cross-sectional views of the specimen. An example of a slice is shown in Figure 2.

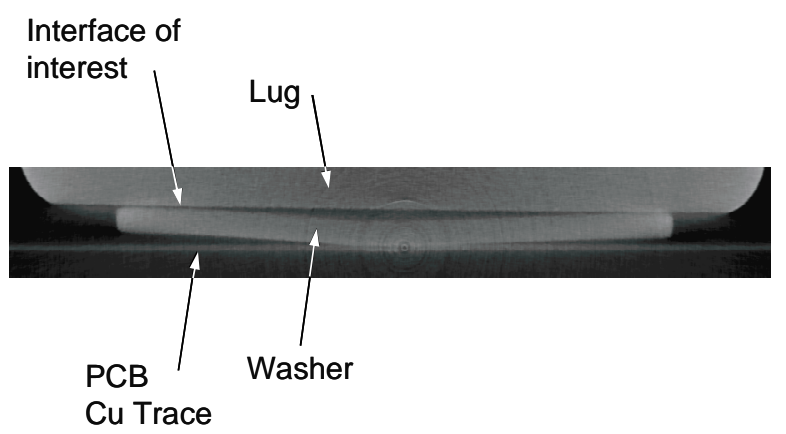

Figure 2 A 2D Slice Image of the Bolted Connection

The 2D slice images are then analysed with a code developed by Lalechos $[11,13]$ to render the 2D "contact map" which identifies the contact areas on the interface. This map consists of approximately $1500 \times 1500$ pixels to a linear resolution of $8 \mu \mathrm{m}$ depending upon the CT scanner set-up. If a pixel is in contact it is assigned the value 1 ; if not in contact it is assigned value 0 . Figure 3 illustrates typical contact maps found by this technique [2]. These contact maps are then used to characterise the contact interface. 


\section{Analysis and Results}

\subsection{Observations from the Contact Maps}

Figure 3 illustrates three contact maps of the bolted connector at different contact forces where the white areas indicate mechanical areas of contact. These white areas consist of "contacting" pixels. Increasing the force results in an increased number of contacting pixels (see Table I) and thus an increase in the mechanical area of contact.
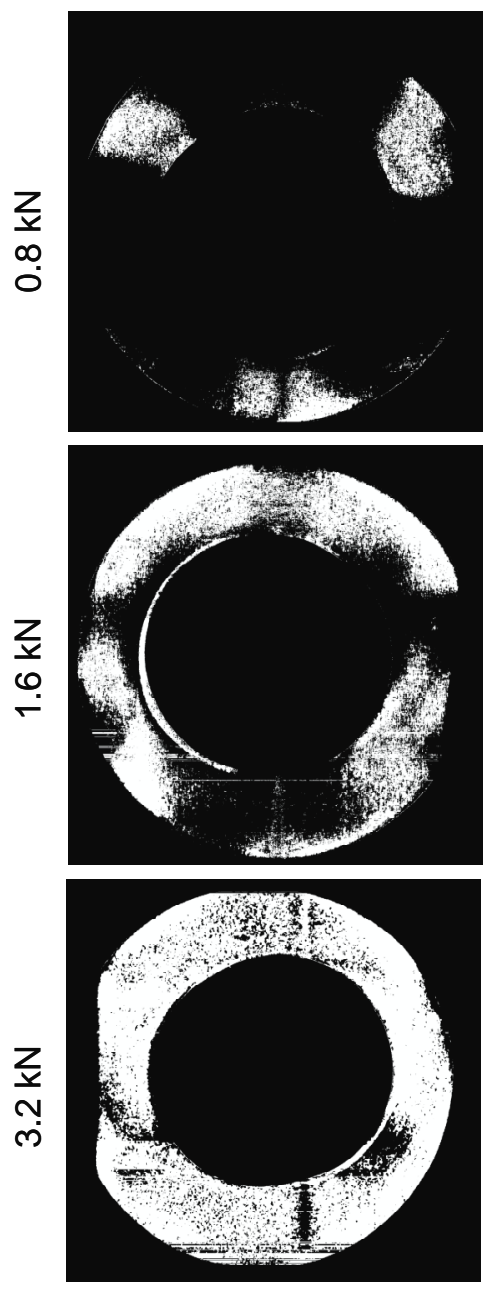

Figure 3 Contact Maps 
In this study, a contact spot is defined as a collection of contacting pixels which are neighbouring other pixels by at least one of their sides. Figure 4 illustrates 3 contact spots: spot 1 consists of 18 contacting pixels, spot 2 consists of only one contacting pixel and spot 3 consists of 10 contact pixels. Note that a pixel which is only a diagonal neighbour with a pixel belonging to a spot is not considered to be a part of that spot (see spot 2 and 3 of Figure 4).

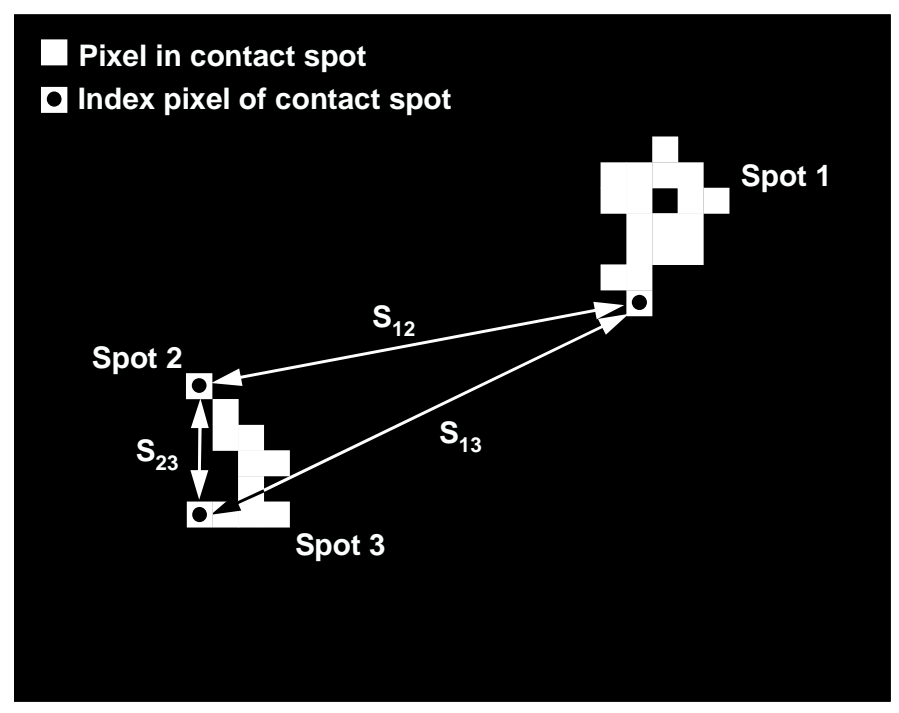

Figure 4 Contact spots and indexing

Table I gives the number of pixels for the specimen of a particular normal force which increases with normal force. However the maximum number of spots is found at $1.6 \mathrm{kN}$.

Table I Characteristics of Maps

\begin{tabular}{ccc}
$\begin{array}{c}\text { Normal } \\
\text { Force / } \\
\text { kN }\end{array}$ & $\begin{array}{c}\text { Number } \\
\text { of Pixels }\end{array}$ & $\begin{array}{c}\text { Number } \\
\text { of Spots }\end{array}$ \\
\hline $\mathbf{0 . 8}$ & $1.32 \times 10^{5}$ & 2714 \\
\hline $\mathbf{1 . 6}$ & $4.64 \times 10^{5}$ & 5945 \\
\hline $\mathbf{3 . 2}$ & $6.34 \times 10^{5}$ & 1226 \\
\hline
\end{tabular}

Figure 5 shows three maps relating to the three contact forces applied. These maps are close-up views of an edge portion of the largest spot on each specimen. The white areas indicate areas of contact and the black areas indicate areas of non-contact. 
At the lower force level of $0.8 \mathrm{kN}$ the largest spot is perforated with many areas of non-contact (lakes). The perimeter (coastline) of the spot meanders with a "peninsulas" and "fjords" structures. Many differently sized islands of contact spots can be seen around the edge of this largest spot. At the higher force level of $3.2 \mathrm{kN}$, the largest spot has fewer lakes and fewer smaller spots.

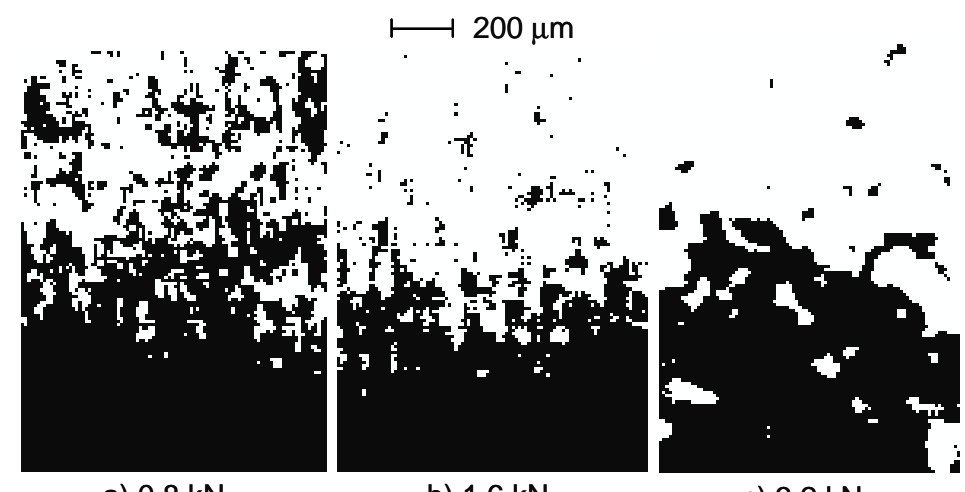

a) $0.8 \mathrm{kN}$

b) $1.6 \mathrm{kN}$

c) $3.2 \mathrm{kN}$

Figure 5 Maps of Close-up Views at the Edge of a Large Spot at Different Normal Force 


\subsection{Pixel spatial distribution investigation}

The clustering of contacting pixels is investigated by determining the number of pixels separated by distance $\mathrm{s}_{\mathrm{ij}}$. (note: lower case s refers to pixels and upper case $\mathrm{S}$ refers to spots in this study). Figure 6 contains three graphs showing the cumulative pixel separation distribution function $\mathrm{N}_{\mathrm{p}}\left(\mathrm{s}_{\mathrm{ij}} \leq \mathrm{s}_{\mathrm{ref}}\right)$ for each of the three contact forces applied. $\mathrm{N}_{\mathrm{p}}\left(\mathrm{s}_{\mathrm{ij}} \leq \mathrm{s}_{\mathrm{ref}}\right)$ is the number of pixels with a separation less than or the same as a reference pixel separation, $s_{\text {ref }}$. This data is shown up to a maximum separation of $6 \mathrm{~mm}$.

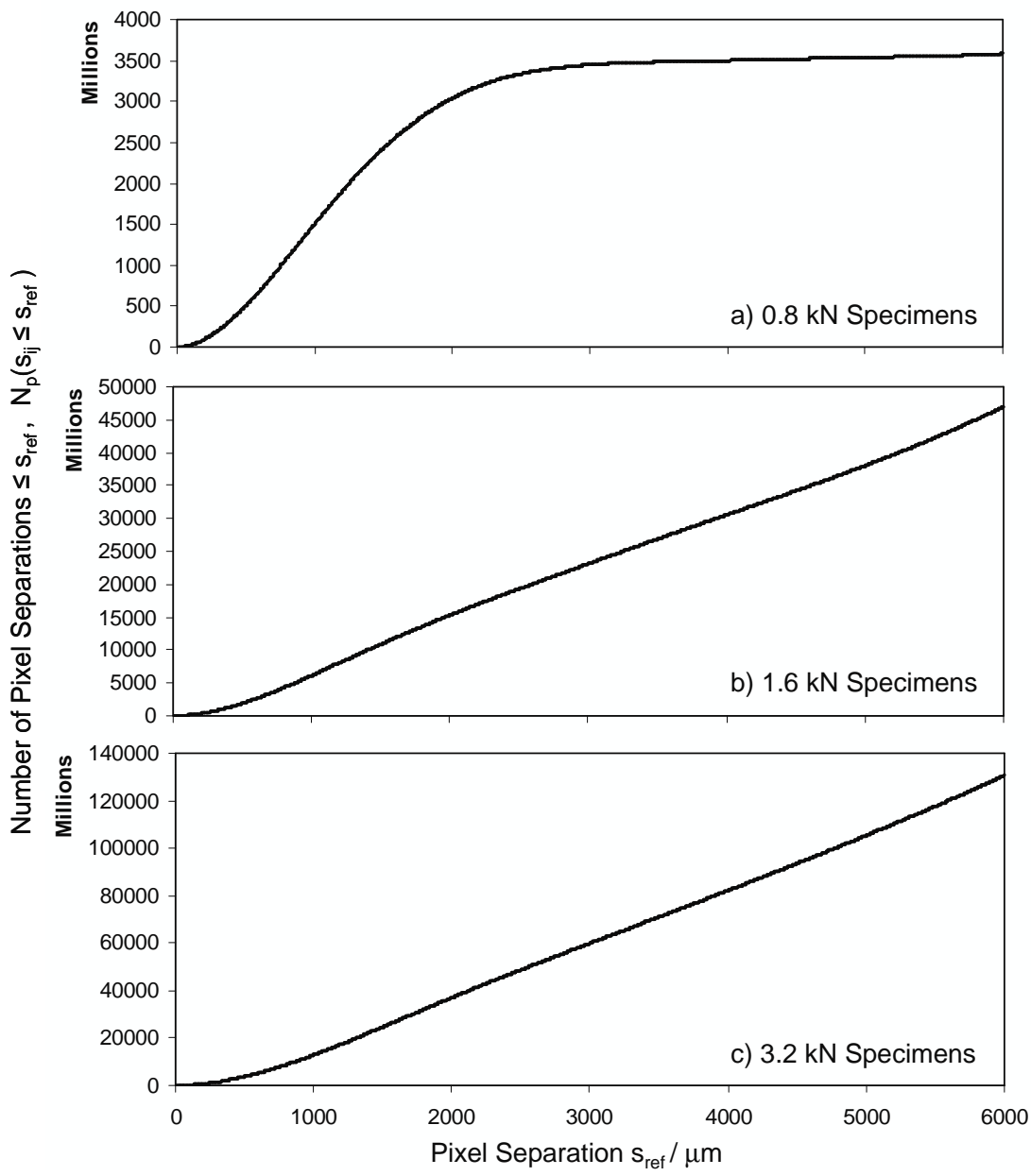

Figure 6 Contacting Cumulative Pixel Spatial Distribution Functions 


\subsection{Spot spatial distribution investigation}

In the spot spatial distribution $n_{s}\left(S_{i j}\right)$ investigation, the number of spots i which have a separation $S_{\mathrm{ij}}$ with spot $\mathrm{j}$ are analysed. However, defining the separation $S_{\mathrm{ij}}$ of spot $\mathrm{i}$ to spot $\mathrm{j}$ is not trivial as several methods could be used. The first is to define $S_{\mathrm{ij}}$ as the distance between the nearest edges of spot $\mathrm{i}$ to spot $\mathrm{j}$ giving the gap between the spots. The second method is defining $S_{\mathrm{ij}}$ as the distance between the "centre of gravity" of spot $i$ to the "centre of gravity" of spot $j$. When using these methods it should be noted that the spots have intricate shapes as illustrated in Figure 5 which may influence the properties of the spot clusters.

For simplicity in extracting data from the maps, the method used in this study is to identify an index pixel which is the lowest left pixel on the spot (as illustrated in Figure 4) and to use this to identify $S_{i j}$ for a pair of spots. The cumulative spot separation distribution function, $N_{\mathrm{s}}\left(S_{\mathrm{ij}} \leq \mathrm{S}_{\mathrm{ref}}\right)$, is then found using this definition of $S_{i j}$. $N_{s}\left(S_{i j} \leq S_{r e f}\right)$ is the number of spots with this separation less than or the same as a reference spot separation. This is used to determine the spot spatial fractal dimension of $\mathrm{D}_{\mathrm{s}}$ as in Equation 5.

$$
N_{s}\left(S_{i j} \leq S_{r e f}\right)=n_{r e s}\left(\frac{S_{r e f}}{S_{r e s}}\right)^{D_{s}}
$$

Where $\mathrm{n}_{\text {res }}$ is defined as the number of spots $\mathrm{i}$ separated from spots $\mathrm{j}$ by the resolution of the technique $(8 \mu \mathrm{m})$. Note that these are spots which are diagonally placed with other spots by $\sqrt{2 \times(8 \mu \mathrm{m})^{2}}$ which rounds down to $8 \mu \mathrm{m}$. Figure 4 illustrates an example of a diagonally placed single pixel spot near a larger spot.

Figure 7 shows three sets of two graphs for the contact forces investigated. The spot size cumulative distribution, $N\left(A_{i} \geq A_{r e f}\right)$, for spots with size equal or greater the a reference size, and the spot separation cumulative distribution for spots separation equal or smaller than a reference separation, $\mathrm{N}_{\mathrm{s}}\left(\mathrm{S}_{\mathrm{ij}} \leq \mathrm{S}_{\mathrm{ref}}\right)$, are plotted. The cumulative spot separation distribution, $\mathrm{N}\left(\mathrm{S}_{\mathrm{ij}} \leq \mathrm{S}_{\mathrm{ref}}\right)$, as with Equation 5, shows a Korcak type behaviour similar to the cumulative spot size distribution as with Equation 1. The spot spatial fractal dimension, $D_{s}$, is indicated on the figure for each force level. 


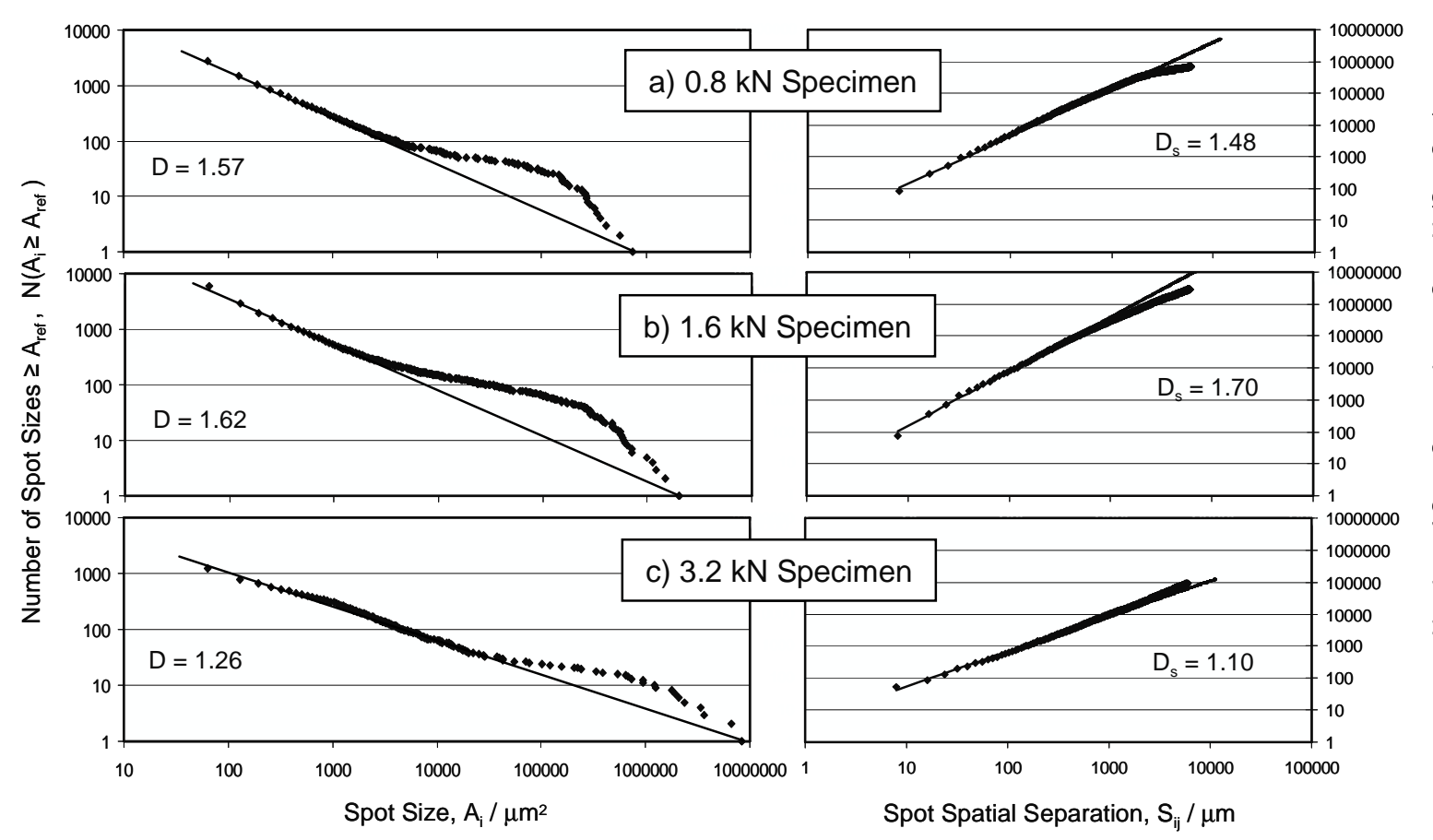

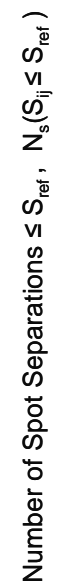

Figure 7 Spot Size and Spatial Cumulative Distribution Functions 


\section{Discussion}

The real un-dismantled contact interface consists of multiple contact spots of different sizes which are dispersed across the apparent area of contact. A complex network of contacting "islands" are observed which have meandering perimeters consisting of contacting "peninsulas" and non-contacting "fjords".

It is found that the spot spatial fractal dimension, $\mathrm{D}_{\mathrm{s}}$, follows a similar trend to the spot size fractal dimension, D, with varying contact forces. That is at the medium normal force value of 1.6 $\mathrm{kN}$, the fractal dimensions are at a maxima and at the highest normal force value of $3.2 \mathrm{kN}$, the fractal dimensions are at a minima. Table II lists some of the interface characteristics where $A_{L}$ is the largest spot, $\mathrm{A}_{\mathrm{m}}$ is the mechanical area of contact and $\mathrm{A}_{\mathrm{a}}$ is the apparent area of contact.

Table II: Summary of the relationship of normal force to surface characteristics

$\begin{array}{cccccc}\begin{array}{c}\text { Normal } \\ \text { Force } / \\ \mathbf{k N}\end{array} & \begin{array}{c}\text { Number of } \\ \text { Spots }\end{array} & \begin{array}{c}\text { Spot Area } \\ \text { Dimension } \\ \mathbf{D}\end{array} & \mathbf{A}_{\mathbf{L}} / \mathbf{A}_{\mathbf{m}} & \begin{array}{c}\mathbf{A}_{\mathbf{m}} / \mathbf{A}_{\mathbf{a}} \\ \mathbf{\pm 5 \%}\end{array} & \begin{array}{c}\text { Spot Spatial } \\ \text { Dimension } \\ \mathbf{D}_{\mathbf{s}}\end{array} \\ \mathbf{0 . 8} & 2.71 \times 10^{3} & 1.57 & 0.080 & 0.118 & 1.48 \\ \mathbf{1 . 6} & 5.95 \times 10^{3} & 1.62 & 0.067 & 0.378 & 1.70 \\ \mathbf{3 . 2} & 1.23 \times 10^{3} & 1.26 & 0.204 & 0.647 & 1.10\end{array}$

Increasing the contact force from $0.8 \mathrm{kN}$ to $1.6 \mathrm{kN}$ results in an increase in the spot size fractal dimension, $\mathrm{D}$, which indicates that the spot number is increasing at a faster rate than an increase in the areas of the spots. The decrease in the $A_{L} / A_{m}$ ratio (the ratio of largest spot size, $A_{L}$, to the mechanical area of contact, $A_{m}$ ) shows that the largest spot is growing at a smaller rate compared to the mechanical area of contact which may give an indication that generally all spots are not growing as fast as the mechanical area of contact. The spot spatial fractal dimension, $\mathrm{D}_{\mathrm{s}}$, also increases with an increase of force from $0.8 \mathrm{kN}$ to $1.6 \mathrm{kN}$ which indicates that the spot number (or more precisely interaction between spots) is increasing at a faster rate than an increase in the spatial separation of spots. Once again this indicates that by flattening the tripedal wavy washer, a dispersion of multiple smaller spots fill the apparent area of contact.

Increasing the contact force from $1.6 \mathrm{kN}$ to $3.2 \mathrm{kN}$ results in a large decrease in the spot size fractal dimension, $\mathrm{D}$, which indicates that the areas of the spots are increasing at a faster rate than the spot number. As can be seen from Table II the spot number is actually reducing so that all spots are increasing in size as indicated by the $A_{L} / A_{m}$ ratio. The spot spatial fractal dimension, $D_{s}$, also decreases with an increase of contact force from $1.6 \mathrm{kN}$ to $3.2 \mathrm{kN}$ which indicates a decrease in spot number with an increase in spot separation. A condition is reached where the boundary of the apparent area of contact has an influence on the growth of the number of spots. As a consequence, the $A_{L} / A_{m}$ ratio increases and there are fewer spots with smaller spot spatial separation. Therefore the fractal dimension decreases which has the possibility of converging to 1. 


\section{Conclusion}

The X-Ray CT technique successfully renders contact maps to a resolution of $8.0 \mu \mathrm{m} \times 8.0 \mu \mathrm{m}$ $\left(64.0 \times 10^{-6} \mathrm{~mm}^{2}\right)$ in the $\mathrm{x}-\mathrm{y}$ plane for a sampling length of $12 \mathrm{~mm}$. The advantage of this technique is to visualize the mechanical area of contact without the need to dismantle the specimens and thus to alter the surface topology. The contact maps contain information on the size distribution, spatial distribution, and shape of the contact spots across the apparent area of contact. Bolted connector interfaces are investigated at different force levels which reveal a complex network of contact spots or "islands". These "islands" have meandering perimeters, consisting of contacting "peninsulas" and non-contacting "fjords", and non-contacting "lakes" within the "islands" which also have meandering perimeters.

The spot spatial distribution is found to exhibit a Korcak type empirical number-separation relationship with fractal behaviour. It is found that the spot spatial fractal dimension varies with contact force in a similar fashion to the spot size fractal dimension.

\section{References}

[1] Slade P. (Ed) 1999 "Electrical Contacts: Principles and Applications", Marcel Dekker Inc USA.

[2] Swingler, J. \& Lalechos A., 2009, "Visualization and size distribution of contact spots at a real un-dismantled electrical contact interface", J. Phys. D: Appl. Phys., 42, doi:10.1088/0022$3727 / 42 / 8 / 085304$

[3] Mandelbrot B., 1975, "Stochastic Models for the Earth's Relief, the Shape and Fractal Dimension of the Coastlines, and the Number-Area Rule for Islands", Proc. Nat. Acad. Sci. USA, 72, No.10, 3825-3828.

[4] Singer M.T., 1991, "Electrical Resistance of Random Rough Contacting Surfaces Using Fractal Surface Modeling.", Proc of the IEEE Holm Conf on Electrical Contacts Chicago, USA, 73-82.

[5] Bhushan B., (ed) 1999, Handbook of Micro/Nano Tribology, $2^{\text {nd }}$ Edition, CRC Press.

[6] Greenwood J.A. 1966 "Constriction Resistance and the Real Area of Contact.", Brit. J. Appl. Phys. 17, 1621-1632.

[7] Jang, Yong Hoon, \& Barber, J.R., 2003, "Effect of Contact Statistics on Electrical Contact Resistance.”, J. of Applied Physics Vol.94, No.11, pp7215-7221.

[8] Ciavarella, M., Greenwood, J.A. \& Paggi, M., 2008, "Inclusion of "Interaction" in the Greenwood and Williamson Contact Theory.", Wear, Vol.265, pp729-734.

[9] Ciavarella, M., Delfine, V. \& Demelio, G., 2006, "A 'RE-vitalized' Geenwood and Williamson Model of Elastic Contact between Fractal Surfaces.”, J.Mech. Phys. Solids Vol.54, pp2569-2591.

[10] Greenwood J.A. \& Willamson J.B.P. 1966 "Contact of Nominally Flat Surfaces.”, Proc of Royal Society, A, 295, 300-319.

[11] Lalechos A.V., Swingler J. and Crane J., 2008, "In Situ Measurement of the Mechanical Contact Area of a High Current Interface" Proc of Int Conf on Electrical Contacts. St. Malo, France, 240-245.

[12] Arumala J., McCulley R. and Yilmaz E., 2000, "The Relationship between the tightening torque and the clamp force of small industrial screw fasteners", ASEE Annual Conference Proceedings, 2000 ASEE Annual Conference and Exposition: Engineering Education Beyond the Millennium, (St. Louis, MO, USA) pp 6101-6118. 
[13] Lalechos A.V., Swingler J. \& Crane J., 2008, "Visualisation of the Contact Area for Different Contact Forces using X-Ray Computer Tomography.", IEEE Holm Conf . on Electrical Contacts, Orlando, FL USA, pp263-269.

\section{Acknowledgement}

Thanks to A. Lalechos for his work on the development of the visualization technique and collecting the raw data used in this study. 